\title{
CARDIOVASCULAR REACTIONS TO GAMMA HYDROXYBUTYRATE IN MAN*
}

\author{
Robert W. Virtue, M.D., LaWRence O. Lund, M.D., HenRy J. BeckwtT, M.D., \\ AND JOHN H. K. VOGEL, M.D. $†$
}

OUR PRELIMINARY EXPERIENCE with gamma hydroxybutyrate ${ }^{1}$ has shown it to be a relatively non-toxic useful hypnotic agent which permits subjects to breathe spontaneously and to maintain adequate blood pressure. It therefore seemed desirable to investigate the cardiovascular effects of the drug in non-operated subjects to obtain data unaltered by surgical procedures.

\section{METHoD}

Eight fasting, healthy volunteer subjects ranging from 22 to 29 years of age, weighing from 52 to $100 \mathrm{~kg}$, were given atropine $0.4 \mathrm{mg}$. and secobarbital 100 mg. each per $70 \mathrm{~kg}$. body weight. A short length of polyethylene 160 tubing was introduced into the brachial artery by the Seldinger ${ }^{2}$ technique. A polyethylene 60 tube was introduced into the antecubital vein either percutaneously or via a 16-gauge thin-walled needle. Control blood pressures were recorded via a $\mathrm{P}_{23 a b}$ transducer. Arterial blood samples were withdrawn for determination of $\mathrm{pH}$, lactic acid dehydrogenase, ${ }^{3}$ serumglutamic oxalotransaminase, ${ }^{4}$ serum glutamic puruvic transaminase, ${ }^{4}$ leucine amino peptidase, ${ }^{5}$ isocitric dehydrogenase, ${ }^{6}$ aldolase ${ }^{7}$ glucose ${ }^{8}$ and urea nitrogen. ${ }^{9}$ Several measurements were made of tidal volume and respiratory rate, until a minimum steady state had been reached. Control tidal volume, respiratory rate, and exhaled air samples were then taken. Cardiac output was measured, the Cardiogreen dye being injected simultaneously with the taking of the air sample. Gamma hydroxybutyrate was administered intravenously over a period of four minutes in a dose of $65 \mathrm{mg} . / \mathrm{kg}$. Beginning five minutes after completion of injection, ventilation and cardiac output measurements were repeated. These measurements were determined at approximately five-minute intervals for 30 minutes. Atropine was injected at varying intervals into five of the eight subjects, with measurements of ventilation and cardiac output being made five minutes after each administration of atropine. Arterial blood was withdrawn just before the termination of each anaesthetic for the same determinations that had been made preanaesthetically.

\section{Results}

After administration of gamma hydroxybutyrate, adequate spontaneous ventilation was maintained with little change in control rate or volume (Table I).

-Supported by a grant from the Wyeth Company.

†Division of Anesthesiology and Cardiovascular Pulmonary Laboratory, University of Colorado Medical Center, Denver, Colorado. Dr. Beckwitt and Dr. Vogel received support from the American Heart Association and the Idaho Heart Association respectively. 


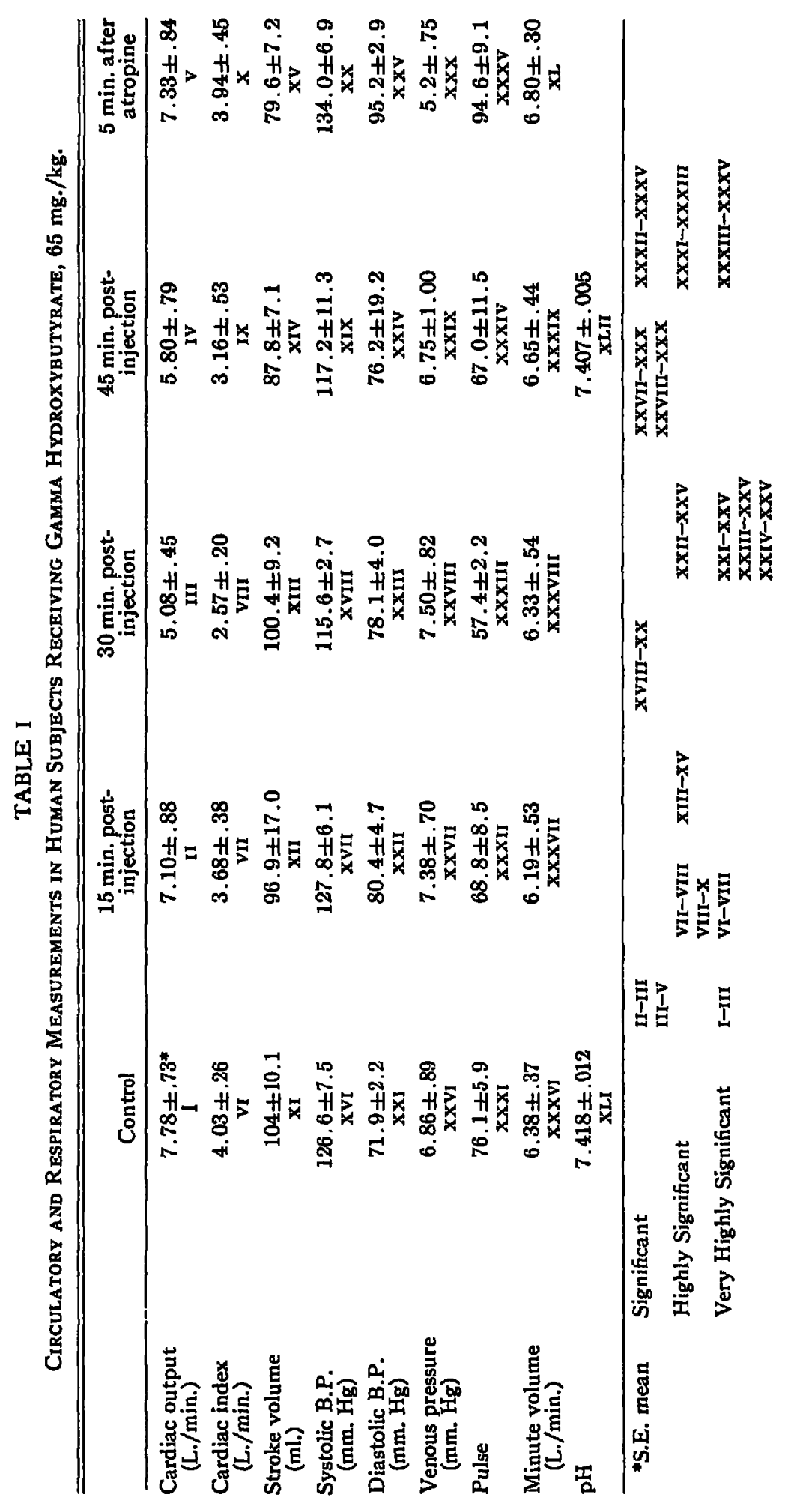




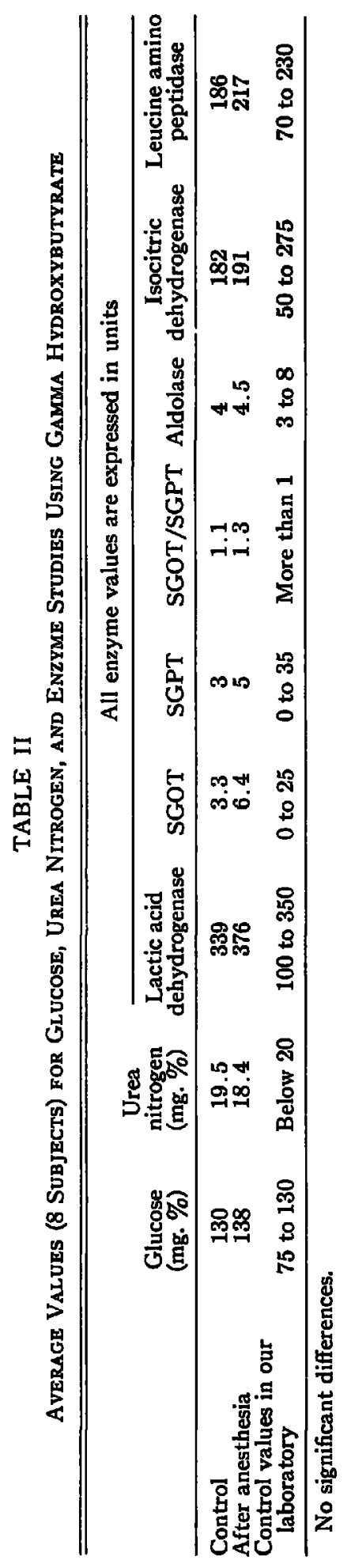


Systemic and central venous blood pressures were stable. $\mathrm{pH}$ was essentially unchanged. The heart rate generally slowed somewhat, and the cardiac output diminished in seven of the eight subjects, reaching a minimum in about 30 minutes. The reduced cardiac output was concomitant with decreased rate in three subjects, and concomitant with a decrease in both rate and stroke volume in four. In two of the five subjects receiving atropine after the pulse had slowed there was an increase of heart rate and a corresponding increase in cardiac output. In the other three subjects both heart rate and stroke volume increased with atropine. Administration of atropine in all cases was followed by an increased arterial pressure and a decreased venous pressure.

Gamma hydroxybutyrate in the doses used did not produce a deep sleep. The lid reflexes disappeared, but there was little analgesia. The E.E.G. showed disappearance of the awake pattern, and appearance of slower waves of higher voltage. Induction was pleasant. When the subjects awakened they were immediately alert, their state contrasting with the drowsy feeling experienced after the commonly used intravenous agent, thiopental. Three subjects who attempted to move about as soon as they had wakened were nauseated for a few minutes. Duration of sleep was about two hours after the administration of the drug, and ranged from 65 to 250 minutes. Post-anaesthesia enzyme, glucose, and urea nitrogen figures were essentially identical with control data (Table II).

\section{Discussion}

Gamma hydroxybutyrate appears to be a basal sedative agent which permits the subject to breathe well spontaneously. Since it has little analgesic property, any noxious stimulus is likely to produce a sympathomimetic response (vasoconstriction). Without such stimulus the heart rate diminishes, but will increase upon administration of atropine. Our previous experiences ${ }^{1}$ with surgical patients, in contrast to these subjects who received the drug without stimuli, indicated that operative stimulus was quite adequate to engender responses that maintain or even increased blood pressure. In the absence of surgical stimulus, present results indicate that atropine permitted circulatory values to resume control levels. Laryngeal reflexes were depressed, for endotracheal intubation was easily performed, and bucking on the tube was slight unless stimuli were present. The drug seems to have potential for such procedures as bronchoscopy and other situations with the patient asleep where spontaneous respiration is desirable.

\section{SUMDMaRY}

Eight volunteer subjects were put to sleep with $65 \mathrm{mg} . / \mathrm{kg}$. of gamma hydroxybutyrate. Respiratory function and cardiac output were determined. Cardiac output diminished, related to a reduction of either cardiac rate or stroke volume or both, and increased again to control levels on administration of atropine. Spontaneous respiration was well maintained. Once the subject had recovered, he rapidly became alert without residual depression. 
VIRTUE, et al.: CARDIOVASCULAR REACTIONS TO GAMMA HYDROXYBUTYRATE 123

Several serum enzyme activities, blood glucose, and blood urea nitrogen values remained at control levels throughout the anaesthetic period.

\section{RÉSUMÉ}

Huit volontaires ont été endormis au "gamma hydroxybutyrate" à la dose de 65 milligrammes par kilo. On a étudié la fonction respiratoire et le débit cardiaque. Le débit cardiaque fut diminué, en rapport avec une diminution du rythme cardiaque ou du débit systolique ou des deux, puis augmenté par l'administration d'atropine. La respiration spontanée s'est maintenue. Après le réveil, le sujet est devenu rapidement actif sans trace de dépression.

Plusieurs activités enzymatiques du sérum, le glucose sanguin et l'urée sanguine sont demeurés dans les limites de la normale au cours de l'anesthésie.

\section{ACKNOWLEDGMENT}

The authors wish to thank Daniel Cooley for his aid in the technical determinations of cardiac output and his assistance with the calculations.

\section{REFERENCES}

1. Lund, L. O.; Humpermes, J. H.; \& VIRTuE, R. W. Sodium Gamma Hydroxybutyrate: Laboratory and Clinical Studies. Canad. Anaesth. Soc. J. 12: 379 (1965).

2. Setonnger, S. I. Catheter Replacement of the Needle in Percutaneous Arteriography: A New Technique. Acta. Radiol. 39: 368 (1953).

3. Wroblewski, F. \& Gregory, K. Lactic Acid Dehydrogenase Isoenzymes and Their Distribution in Normal Tissue and Plasma in Disease States. Ann. New York Acad. Sc. 94: 912 (1961).

4. Rerman, S. \& Frankis, S. A Colorimetric Method for the Determination of Serum Glutamic Oxaloacetic and Glutamic Pyruvic Transaminase. Am. J. Clin. Path. 28: 56 (1957).

5. Green, M. N.; Tsou, K.-C.; Bressluer, R.; \& Seligman, A. M. The Colorimetric Determination of Leucine Aminopeptidase Activity with L-Leucyl- $\beta$-Naphthylamide Hydrochloride. Arch. Biochem. 57: 458 ( 1955).

6. BELL, J, K. \& BARON, D. N. Colorimetric Estimation of Serum Isocitric Dehydrogenase. J. Clin. Path. 12: 582 (1959).

7. Snlbey, J. A. \& Lehnnger, A. H. Determination of Aldolase in Animal Tissues. J. Biol. Chem. 177: 859 (1949).

8. Netson, N. Photometric Adaption of Somogyi Method for Determination of Glucose. J. Biol. Chem. 153: 375 (1944).

9. KArr, W. G. Method for Determination of Blood Urea Nitrogen. J. Lab. \& Clin. Med. 9: 329 (1924). 